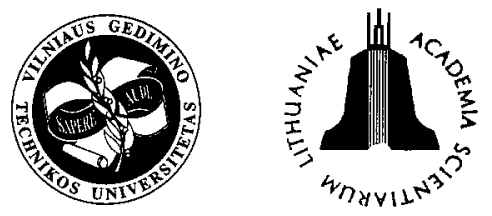

JOURNAL OF CIVIL ENGINEERING AND MANAGEMENT

http:/www.vtu.lt/english/editions

2003, Vol IX, No 4, 266-270

\title{
EFFECT OF REDISTRIBUTION OF INTERNAL FORCES ON FIRE RESISTANCE OF FLEXURAL REINFORCED CONCRETE MEMBERS
}

\author{
Zoja Bednarek \\ The Main School of Fire Service in Warsaw, 01-629 Warsaw, \\ J.Stowackiego 52/54.E-mail: sgsp@sgsp.edn.pl
}

Received 18 Jan 2003; accepted 05 Sept 2003

\begin{abstract}
In this paper the author presents the results of experiments with the three steel grades under thermal conditions of the standard fire with account of the change of stress in steel samples, similar to changes of stress in the reinforcement, resulting from redistribution of bending moments. The major purpose of the experiments was to find out whether it would be possible to take into account the redistribution of bending moments of reinforced concrete members by the method developed by the author for determining the critical temperature and the time till failure of reinforcement of the concrete bended members.
\end{abstract}

Keywords: concrete structures, fire resistance, standard fire, redistribution of bending moments, reinforcement, change of stress, critical temperature, time till failure.

\section{Introduction}

None of the analytical methods available for determining the fire resistance of reinforced concrete structures accounts for redistribution of the internal forces resulting from high temperatures.

Redistribution of bending moments is not taken into consideration in the method advanced by the author [1-6] for determining the critical temperature for the reinforcement and the time till failure of reinforced concrete slabs. Meanwhile, this effect occurs in nearly all elements subjected to bending, eg beams, transoms, slabs, etc. Even in case of simply supported beams or slabs, once the free deflection possibility is exhausted and the static scheme becomes changed during a fire, redistribution of bending moments takes place [6]. Relevant studies demonstrate a significant decrease in bending moments in the middle of the span and their increase at the supports during the first 15 minutes of the fire and then a reverse cycle starts: an increase in bending moment values in the middle of the span and a decrease of the corresponding values at the supports [6].

In this paper the author presents the results of the studies on St3, 18G2 and 34GS steel grades under thermal conditions of the standard fire with an account of the change in stresses in steel samples similar to the reinforcement stress changes resulting from redistribution of bending moments.

\section{Major objective of the study and assumptions}

The aim was to find out whether it would be possible to account for the redistribution of stress level in the reinforcement of flexural reinforced-concrete members by the author's developed method for determining critical temperature and the time till failure of the reinforcement under standard fire conditions. The method is based on the results of studies into reinforcing steel at a constant stress level $\sigma / R_{e}=$ const and in the time-variable temperature field determined by the temperaturetime curve [1-3].

Based on the results of the study, some simple formulas are suggested which determine the critical temperature of steel and the time till failure of the reinforcement which for slabs corresponds to their fire resistance:

$$
T_{k r}=B\left(\sigma R_{e}\right)^{-0,2},
$$

where

$T_{k r}$ - critical temperature, ${ }^{\circ} \mathrm{C} ; \sigma / R_{\mathcal{e}}$ - the stress level in the reinforcement prior to temperature rise; $B$ - material constant corresponding to the critical temperature of steel at a stress $\sigma=R_{e}$ determined experimentally for a given material and a temperature distribution

$$
\tau_{k r}=A\left(\sigma / R_{e}\right)^{-0,5}
$$

where

$\tau_{k r}$ - critical time assumed as the time from the start of the heating till failure of the reinforcement; $A$ - material 
constant corresponding to the time elapsed till failure of sample at $\sigma / R_{e}$ which is determined experimentally along with $B$ constant.

Fig 1 shows the curves that describe the critical temperature for St3 grade steel:

- used for reinforcement according to Eurocode ENV 1992-1-2 (marked with c)

- used for structural steel according to Eurocode ENV 1993-1-2 (marked with d)

- the curve obtained by $Z$. Bednarek and described by formula (1) (marked with a)

This figure also shows the curve of decreasing steel plastic limit at high temperatures (marked with b). On the basis of this curve, critical temperature was determined using an outdated method [5].

Prior to the experimental study it was assumed that the double change in the stress level in the reinforcement which consists in its lowering during the test followed by its rise should not bring about negative results in the form of a reduced critical temperature and the time till the sample failure. As the stress rise during the second change would not attain the original level (this is the case of redistribution of bending moments), a value rise of these parameters desirable from the standpoint of fire resistance of a structure should be anticipated. It was also assumed that for determining critical temperature, $T_{k r}$, and time till failure, $\tau_{k r}$, formulas (1) and (2) can be used in which the weighted-average stress level will replace the constant stress level, viz:

$$
\begin{gathered}
T_{k r}=B\left(\sigma / R_{e}\right)_{w t . a v}^{-0,2}, \\
\tau_{k r}=A\left(\sigma R_{e}\right)_{w t . a v .}^{-0,5} .
\end{gathered}
$$

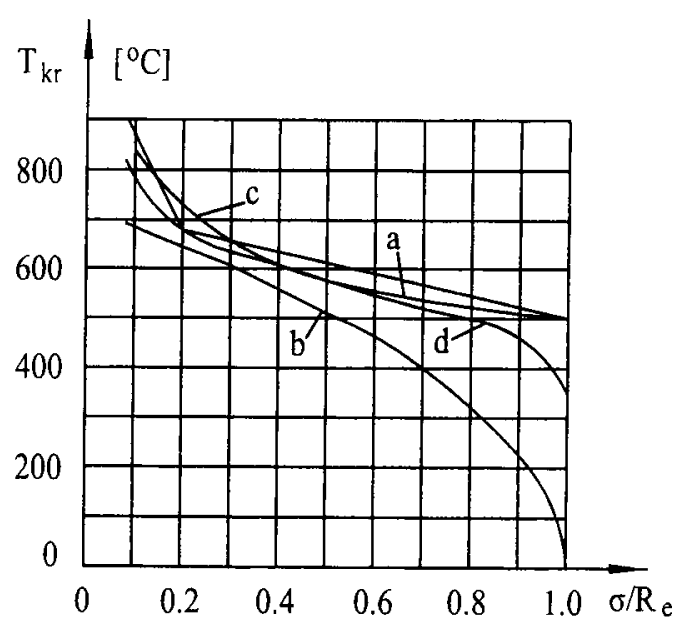

Fig 1. The critical temperature of St3 grade steel: a after the $Z$. Bednarek method, $b$ - after the plastic limit fall curve, c - after the ENV 1992-1-2 (for reinforcing steel), d - after the ENV 1993-1-2 (for structural steel)

\section{Testing method}

\section{- Thermal conditions}

The temperature vs time distribution was assumed which occurs in concrete at a depth of $25 \mathrm{~mm}$ during a standard fire. The distribution is obtained by analytical method on the assumption of an adequate physical and mathematical model for concrete and by using numerical methods for solving Fourier thermal conduction equations. The method for determining the temperature $v s$. time distributions and the concrete model assumed are covered in $[1,2]$.

\section{- Sample loading}

Two variants of loading were used: constant or variable loading.

At a constant stress level $\sigma R_{e}=$ const 1 . the material constants $A$ and $B$ were determined. The aim of these tests was to obtain parameters for comparative analysis.

2. The tests were carried out at a variable stress level. Variations in the level were found from an analysis of studies of redistributing bending moments in continuous beams under standard fire conditions.

Values of these bending moments are presented in Table 1 . The values of the moments preceding the heating were assumed as $100 \%$.

Table 1. Values of the redistribution of the bending moments

\begin{tabular}{|c|c|c|}
\hline $\begin{array}{c}\text { Standard fire } \\
\text { time, min }\end{array}$ & $\begin{array}{c}\text { Bending } \\
\text { moments in } \\
\text { span, \% }\end{array}$ & $\begin{array}{c}\text { Bending } \\
\text { moments at } \\
\text { supports, \% }\end{array}$ \\
\hline 0 & 100 & 100 \\
\hline 15 & 35 & 220 \\
\hline 160 & 79 & 130 \\
\hline
\end{tabular}

As the temperature rises during the fire from the bottom part of the floor and first of all it concerns the temperature rise of the bottom reinforcement being tensioned, it was found that the stress level change in samples during testing will coincide with the redistribution of the bending moments in the span (100\%, 35\%, $79 \%$ ). It was found that the initial (prior to heating) stress level value will be equal to 0,67 , a subsequent one that occurs about. $15 \mathrm{~min}$ later $-0,23$, and the last following the rise $-0,53$. It was also found that the rate of stress decline and of the subsequent rise will be equal to the relaxation time of the steel grade examined, as obtained by the experimental method.

The study was carried out on samples made of St3, 18G2 and 34GS steel grades.

\section{- Procedure}

The testing scheme with a variable stress level is shown in Fig 2. 


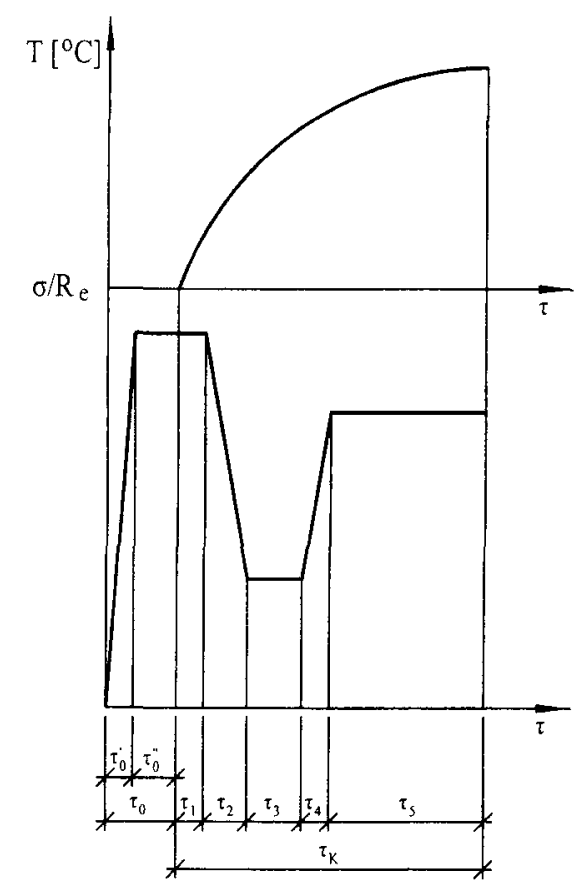

Fig 2. Diagram of the testing procedure: $\tau_{0}-$ the time after which the assumed load and temperature $50^{\circ} \mathrm{C}$ are attained; $\tau_{k}-$ test duration time

The sample load assumed which corresponds to a stress level $\sigma / R_{e}=0,67$ was applied prior to the heating and was maintained for $5 \mathrm{~min}$ from the moment the temperature of $50^{\circ} \mathrm{C}$ was attained as measured at the point the thermocouples were fitted. Subsequently, the constantforce maintaining device was released, and as soon as the force decreased because of the effect of rising temperature to a value corresponding to a stress level of $\sigma / R_{e}=0,23$, the testing machine was turned again to maintain a constant force which was maintained for $10 \mathrm{~min}$. The subsequent rise in the force to a value corresponding to $\sigma / R_{e}=0,53$ was forced and proceeded at a rate identical with the force falling rate. The force was maintained at a constant value till failure of the sample.

Shown in Fig 3 is the varying stress level in samples obtained in the testing. The curves were used to establish the weighted-average stress level in samples during testing.

\section{Results of experiments}

\section{- Determination of material constants A and B}

Results of the experiments at constant stress levels $\sigma / R_{e}=0,67,0,53$ and 0,23 were worked out to evaluate the material constants $A$ and $B$. For each stress level 5 samples each were studied to find $T_{k r}$ and $\tau_{k r}$ [1] [2]. The $A_{i}$ and $B_{i}$ constants were evaluated for each stress level $i=1$ to 3 from formulas:

$$
A_{i}=\tau_{k r} \sqrt{\sigma R_{e}},
$$

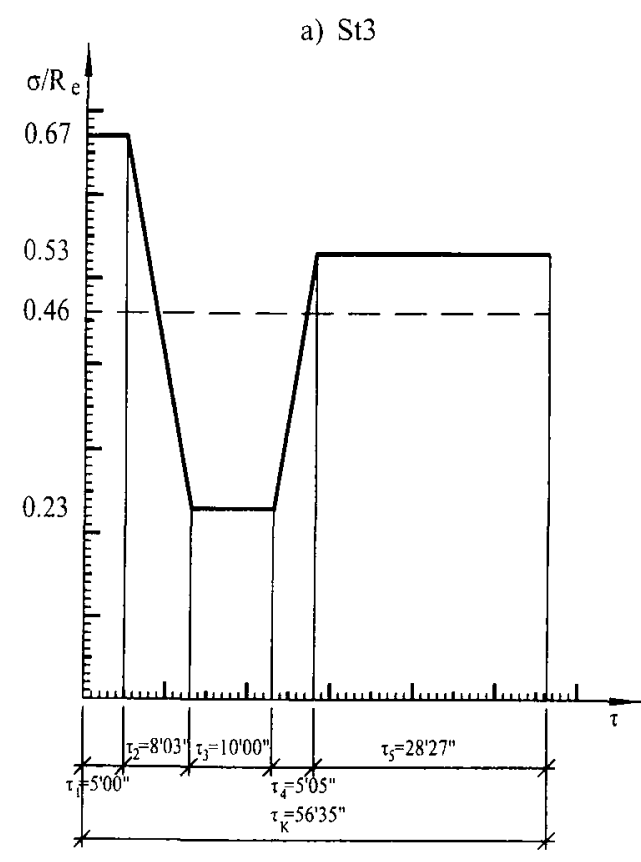

b) $18 \mathrm{G} 2$

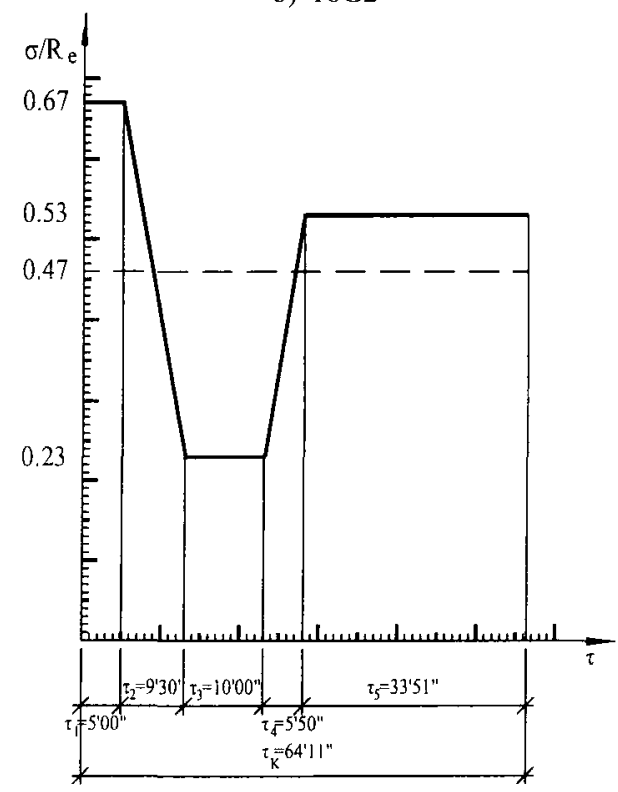

Fig 3. Determination of the weighted-average stress level: a - St 3 and 34GS steel grades, b-18G2 steel grade

$$
B_{i}=T_{k r} \sqrt[5]{\sigma R_{e}}
$$

The $A$ and $B$ constants were used in subsequent calculations as an arithmetic mean $A=(A 1+A 2+A 3) / 3$, $B=(B 1+B 2+B 3) / 3$. In Table 2 values of the material constants $A$ and $B$ for three steel grades are presented.

On the basis of the plots shown in Fig 3, the weighted-average stress level was evaluated in samples studied with variable stress level. It is equal to 0,46 for St3 and 34GS steel grades and 0,47 for $18 \mathrm{G} 2$ steel grade. A series of tests at constant weighted-average stress levels were carried out. Results of these tests as $T_{k r}$ and $\tau_{k r}$. parameters are useful in comparative analysis. 
Table 2. Values of the material constants $A$ and $B$ for three steel grades

\begin{tabular}{|c|c|c|c|c|}
\hline \multirow{2}{*}{$\begin{array}{c}\text { Steel } \\
\text { grade }\end{array}$} & \multirow{2}{*}{$\begin{array}{c}\text { Stress } \\
\text { level } \sigma / R_{e}\end{array}$} & \multicolumn{2}{|c|}{ Material constants } & Numbe \\
& & $\mathrm{A}, \mathrm{min}$ & $\mathrm{B},{ }^{\circ} \mathrm{C}$ & $\begin{array}{c}\text { of } \\
\text { samples }\end{array}$ \\
\hline \multirow{3}{*}{$\mathrm{St3} 3$} & 0,67 & & & \\
& 0,23 & 37,24 & 492,48 & 15 \\
& 0,53 & & & \\
\hline \multirow{3}{*}{$18 \mathrm{G} 2$} & 0,67 & & & \\
& 0,23 & 43,87 & 517,29 & 15 \\
& 0,53 & & & \\
\hline \multirow{3}{*}{$34 \mathrm{GS}$} & 0,67 & & & \\
& 0,23 & 44,39 & 534,91 & 15 \\
\hline
\end{tabular}

\section{- Testing at variable stress level}

The tests were run as shown in Figs 2 and 3. Times $\tau_{2}, \tau_{4}, \tau_{5}$ were estimated as the means from five tests. Times $\tau_{1}$ and $\tau_{3}$ were assumed a priori, and the fall of the stress level to the lowest value occurs in the time $\tau_{1}+\tau_{2}$ equal to about $15 \mathrm{~min}$. Evaluation of the $T_{k r}$ and $\tau_{k r}$ parameters was made on the basis of the set of $T-\tau$ (temperature - time) and $\varepsilon-\tau$ (strain - time) plots obtained for each sample as in the study with constant stress levels [1] $\div[5]$. The $T_{k r}$ and $\tau_{k r}$ parameters obtained on the basis of the results of the study are gathered in Table 3. Also gathered in this table are the values of the parameters obtained from tests at a constant stress level: original $\sigma / R_{e}=0,67$, weighted-average $\sigma / R_{e}=0,46$ (for St3 steel and $34 \mathrm{G}$ steel), and $\sigma / R_{e}=0,47$ (for $18 \mathrm{G} 2$ steel), and those obtained using formulas (3) and (4) for the weighted-average level.

*) Calculation of the $T_{k r}$ and $\tau_{k r}$ parameters was made on the assumption of the experimentally found material constants $A$ and $B$ and the weighted-average stress level:

For St3 steel:

$$
\begin{gathered}
\tau_{k r}=37.42(0.46)^{-0.5}=54.90 \mathrm{~min}, \\
T_{k r}=492,48(0,46)^{-0,2}=602^{\circ} \mathrm{C} .
\end{gathered}
$$

For $18 \mathrm{G} 2$ steel:

$$
\begin{gathered}
\tau_{k r}=43,87(0,47)^{-0,5}=63,98 \mathrm{~min}, \\
T_{k r}=517,29(0,47)^{-0,2}=602{ }^{\circ} \mathrm{C} .
\end{gathered}
$$

For $34 \mathrm{GS}$ steel:

$$
\begin{gathered}
\tau_{k r}=44,39(0,46)^{-0,5}=65,20 \mathrm{~min}, \\
T_{k r}=534,91(0,46)^{-0,2}=622^{\circ} \mathrm{C} .
\end{gathered}
$$

\section{Conclusions}

- Redistribution of internal forces in flexural members during a fire is similar to the one described in this study. It consists in a significant decline in the bending moment at the initial stage of the fire followed by a rise at this moment to a value lower than the initial one.

At the same time the moments at the supports significantly rise by analogy. Considering that the floor members are being strongly heated from the bottom of the structure, a decline of the bending moments in the middle of the span, as well as a decrease of stress in the reinforcement of floor members is beneficial from the standpoint of structure stability under fire conditions, as it increases the time of failure of the structure, thus it raises its fire resistance.

- It follows from results of the analysis presented in Table 3 that:

- The critical temperature, $T_{k r}$, and the time till reinforcement failure, $\tau_{k r}$, calculated and measured with an account of the stress level prior to the fire, is lower. Accordingly, in the event the internal forces redistribution in structures under bending is not exactly established, it may be ignored in favour of the strength of the structure under fire conditions.

- Redistribution of the internal forces can be taken into account when evaluating the temperature and time parameters of reinforcing steel grades by the method advanced by the author. In this case the formulas reported in [1] and [2] as well as in this paper should be used on the assumption that a reduced stress level

Table 3. Comparison of experiment and calculation results

\begin{tabular}{|c|c|c|c|c|}
\hline Steel grade & $\begin{array}{c}\text { Stress level } \\
\sigma / R_{e}\end{array}$ & $\begin{array}{c}\text { Time till failure, } \\
\tau_{k r}, \min \end{array}$ & $\begin{array}{c}\text { Critical temperature, } \\
T_{k r}{ }^{\circ} \mathrm{C}\end{array}$ & Notes \\
\hline \multirow{5}{*}{ St3 } & 0,67 & 46,00 & 530 & experiment \\
& 0,46 & 53,85 & 573 & experiment \\
& 0,46 & 54,90 & 575 & calculation*) \\
& variable & 55,17 & 575 & experiment \\
\hline \multirow{4}{*}{$18 \mathrm{G} 2$} & 0,67 & 53,90 & 553 & experiment \\
& 0,47 & 64,81 & 603 & experiment \\
& 0,47 & 63,98 & 602 & calculation $\left.{ }^{*}\right)$ \\
& variable & 63,67 & 603 & experiment \\
\hline \multirow{3}{*}{$34 \mathrm{GS}$} & 0,67 & 54,10 & 581 & experiment \\
& 0,46 & 65,30 & 620 & experiment \\
& 0,46 & 65,20 & 622 & calculation*) \\
& variable & 65,50 & 623 & experiment \\
\hline
\end{tabular}


occurs in place of the constant stress level prior to the fire. The value of this reduced stress is equal to the weighted-average value. The formulas to find the critical temperature, $T_{k r}$, (formula 3 ) and the time till failure, $\tau_{k r}$, (formula 4) are reported in this paper.

- A comparison of the results of calculations and tests gathered in Table 3 confirms usefulness of the method developed by Z. Bednarek [1-3] for determining critical temperatures and times till reinforcement failure under thermal conditions similar to the standard fire conditions.

\section{References}

1. Bednarek, Z. Experimental determining of time and temperature strength parameters on which calculations of fire resistance. Building Construction (Statyba), No 1(1). Vilnius: Technika, 1995, p. 48-58.
2. Bednarek, Z. The effects of increase of temperature on structural steel strength parameters as applied to the estimation of fire safety of concrete construction. Doctoral Habilitation thesis. Vilnius: Technika, 1996, p. 1-208.

3. Bednarek, $Z$. Influence of stress in the tensioned reinforcement on the fire resistance of flexural members. Inżynieria i Budownictwo, 3/1993, p. 119-122.

4. Bednarek, Z. Influence of thermal conditions on strength parameters of reinforcing steel exposed to fire. Inzynieria i Budownictwo, $12 / 1993$, p. $526-528$.

5. Bednarek, Z. Numerical model of fire resistance of building structures. Beton a zdivo, 2/1999, p. 9-14.

6. Bednarek, Z. On estimation of thermal stress and strain conditions in construction exposed to fire. Inzynieria $i$ Budownictwo, 10/1994, p. 458-460.

7. Ódeen, K. Spännbeton under brandangrep, Brandförsvar 2, 1965, Stockholm, Sweden. 